\title{
A simplified time-domain design and implementation of cascaded PI-sliding mode controller for dc-dc converters used in off-grid photovoltaic applications with field test results
}

\author{
LENIN PRAKASH $^{1, *}$, ARUTCHELVI MEENAKSHI SUNDARAM $^{2}$ \\ and STANLEY JESUDAIYAN ${ }^{2}$ \\ ${ }^{1}$ Department of Electrical and Electronics Engineering, Anna University, Chennai 600025, India \\ ${ }^{2}$ Department of Electrical and Electronics Engineering, Saranathan College of Engineering, \\ Trichirappalli 620012, India \\ e-mail: lenin.prakash.s@gmail.com; arutchelvi@gmail.com; stanleyjesudaiyan@gmail.com
}

MS received 6 November 2015; revised 17 October 2016; accepted 4 November 2016

\begin{abstract}
A time-domain design methodology for voltage regulation control of dc-dc boost and buck-boost converters based on a multi-loop controller with PI regulator for the outer loop and an inner loop with sliding mode current controller has been developed for renewable energy applications such as photovoltaic (PV)-fed $\mathrm{dc}-\mathrm{dc}$ converters. This paper proposes a new method for the design of PI regulators in such multi-loop control scheme. The proposed design presents a simple analytical method for selecting controller gains and has been validated by simulation as well as hardware implementation. Also, this paper presents an illustrative example based on the proposed design for the voltage regulation control of PV-fed boost converters for off-grid applications. The simulation results for varying irradiation, temperature and load along with stability analysis have been presented in this paper. The proposed controller is implemented in hardware for a $1.1 \mathrm{~kW}$ PV-array-fed boost converter. Performance analysis based on field test results using real-time weather data validates the proposed design. Therefore the proposed controller could be considered as an attractive solution for off-grid renewable energy applications like PV- or fuel-cell-fed dc-dc converter, where the variations are stochastic in nature.
\end{abstract}

Keywords. dc-dc power converters; PI control; sliding mode control; energy factor; time-domain analysis.

\section{Introduction}

Boost converters and buck-boost converters are invariably used as front-end power interface in renewable energy applications such as photovoltaic (PV) solar systems, fuel cells, etc. [1,2]. When these converters are employed in open-loop mode, they do not provide voltage regulation and exhibit poor dynamic response; hence, these converters require a closed-loop control for regulating the output voltage. The modelling of dc-dc converters is one of the preliminary steps in the design of controllers. Numerous contributions on modelling and control of dc-dc converters have been reported in literature [3-7].

The linearized small-signal transfer function approach was invariably followed in the early years [3, 4, 7]. Numerous methods on closed-loop controller design for $\mathrm{dc}-\mathrm{dc}$ converter, based on this small signal model, have been reported in the literature [8-12]. Some of the methods that could be mentioned are Ziegler-Nichol's method [9],

*For correspondence hysteresis method [12], circle-based criterion [8], etc. Later several methods based on modern control theory are seen in literature based on the state space models such as sliding mode techniques $[11,13]$ and fuzzy controllers [14-16]. In many of these modelling techniques, different models are required for representing converter operation in continuous conduction mode (CCM) and discontinuous conduction mode (DCM), and in the literature previously described, the DCM operation has been overlooked.

In all dc-dc converters, which are basically switching circuits, the energy transfer from source to load takes place in discrete time mode. An absence of correct theory to describe the characteristics of all such switching circuits prevailed until 2004. A new theory and set of parameters has been proposed in Luo et al [17], to describe the behaviour of such switching circuits, in terms of a new concept call energy factor (EF). This concept has paved the way for yet another kind of modelling dc-dc converters with a transfer function with new factors such as time constant and damping time constant, which is applicable for both CCM and DCM operations. This EF-based transfer function 
model of power dc-dc converters is well exploited in the present work for design of PI controllers [18]. Also, current-mode control (CMC) has been widely used for a stringent voltage regulation with huge disturbances in the input voltage. A CMC is a linear feedback along with an integral feedback that consists of an external voltage loop and also an inner current loop. It is also known as multiloop control [19].

In most of the existing works, the design and validation of the controller are performed considering a stiff dc source with some disturbance introduced to it. However, in case of a dc-dc converter fed from a renewable source like photovoltaic (PV) array, the voltage from such sources possesses drooping $V-I$ characteristics and is not stiff; rather it depends on multiple factors that change with time, which include irradiation incident on the PV array and ambient temperature as well as loads connected to the PV array. There are also other factors such as wind speed, dust deposition, shadow, etc. that have some influence on the output of the PV array. It should be noted that the change in $\mathrm{PV}$ voltage due to irradiance and temperature might not be very fast, since the change in irradiation or temperature does not happen instantaneously. However the change in load connected to the PV does happen instantaneously, which causes a rapid change in PV voltage and in turn the magnitude of this change depends upon the irradiance value. The rapidity of the change in PV voltage depends on load as well as the weather condition. Hence there is an appreciable difference between the control of dc-dc converter that is fed by an uncontrolled rectifier connected to grid, which is mostly the case, and the one like a stochastic renewable source such as PV array. So far there is no design procedure for PI controller used in a cascaded PI$\mathrm{SMC}$ that has been reported in the literature for a PV-arrayfed dc-dc converter. For such a scenario, the controller design and its validation have been attempted using the $\mathrm{EF}$ model of a dc-dc converter in the present work for the first time.

This paper proposes a new simple time domain design procedure for multi-loop control of $\mathrm{dc}-\mathrm{dc}$ converter, in order to achieve voltage regulation. The outer loop consists of a PI regulator and the inner loop consists of a sliding mode current controller (SMC). This paper specifically deals with the design of PI regulators in such multi-loop control schemes, which is applied to design a voltage-regulated dc-dc boost and buck-boost converter fed by a stochastic dc source and validated with simulation and field test results. This paper is organized as follows. Section 2 presents the modelling of boost and buck-boost converters. Section 3 presents the proposed design of controllers. Section 4 presents the application of the proposed controller for voltage regulation of PV-array-fed boost converter along with simulation results and stability analysis. The hardware implementation of the proposed controller and field test results are presented in section 5.

\section{Modelling and transfer function of dc-dc boost and buck-boost converter}

The modelling of dc-dc boost converter and buck-boost converter reported in the literature and also the transfer function of these converters as proposed by Dr Fang Lin Luo and Dr Hong Ye [18] have been presented in this section to provide a basis for the subsequent sections.

The equivalent circuit of the boost converter feeding a resistive load, when the switch is closed and open, is shown in figure 1a and $\mathrm{b}$, respectively, where ' $R$ ' represents the load resistance, ' $L$ ' is the inductance and ' $C$ ' is the capacitance. Similarly the equivalent circuit of the buckboost converter feeding a resistive load when the switch is closed and open is shown in figure $2 \mathrm{a}$ and $\mathrm{b}$, respectively.

The generalized transfer function of any dc-dc converter proposed by Fang Lin Luo [18], based on the EF concept is given by the equation

$$
\frac{V_{o}(s)}{V_{\text {in }}(s)}=\frac{M}{1+s \tau+s^{2} \tau \tau_{d}}
$$

where ' $M$ ' is the voltage transfer gain $\left(M=\frac{V_{o}}{V_{i n}}\right), \tau$ is the time constant, $\tau_{d}$ is the damping time constant and $s$ is the Laplace operator in the $s$-domain. The concept of time constant and its definition and derivation are well explained in Luo and Ye [18] and the expressions for these parameters

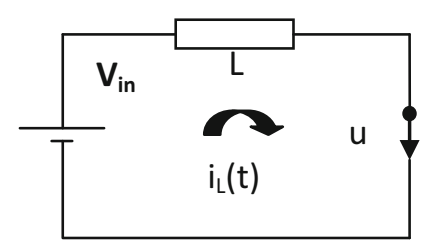

(a)

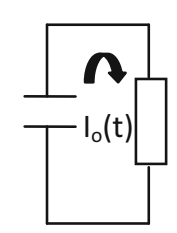

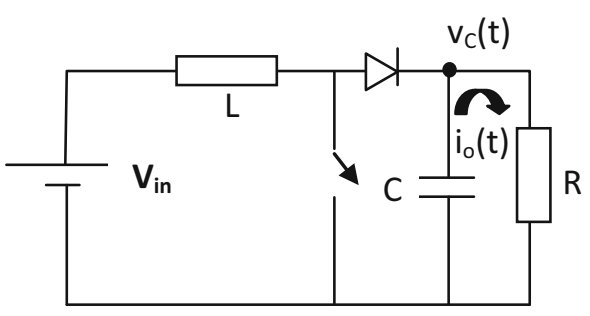

(b)

Figure 1. Equivalent circuit of boost converter with resistive load (a) when the switch is closed and (b) when the switch is open. 


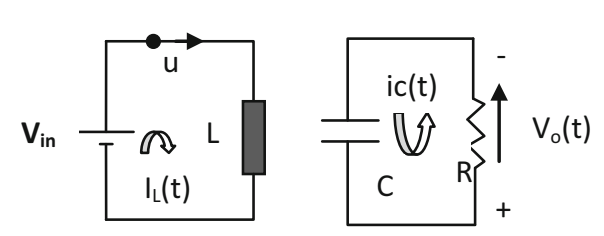

(a)

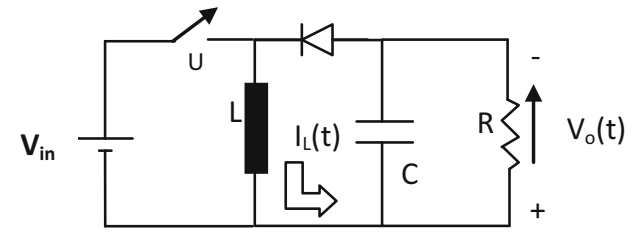

(b)

Figure 2. Equivalent circuit of buck-boost converter with resistive load (a) when the switch is closed and (b) when the switch is open.

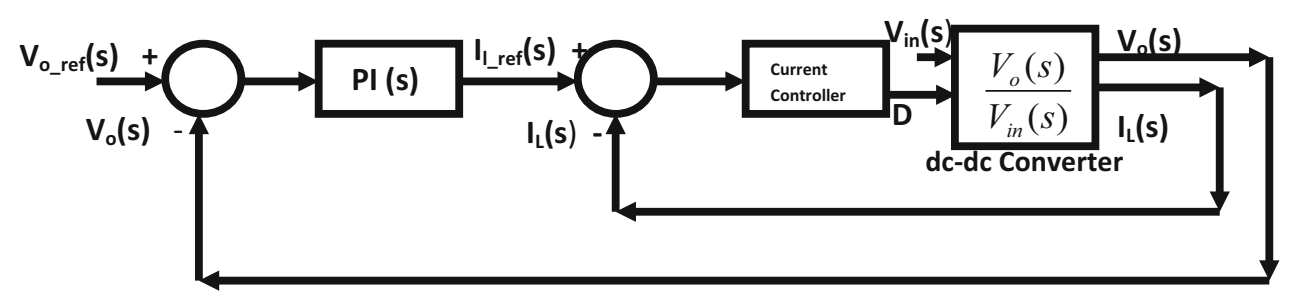

Figure 3. Block diagram for the closed-loop output voltage regulation of a boost converter.

assuming there are no losses in the converter are given by Eqs. (2)-(5).

$$
\tau=\frac{2 T \times E F}{1+C I R}
$$

$E F$ is the energy factor and $C I R$ is capacitor-inductor stored energy ratio, which are given by Eqs. (3) and (4), respectively:

$$
\begin{gathered}
E F=\frac{S E}{P E}=\frac{\sum_{j=1}^{m} W_{L j}+\sum_{j=1}^{n} W_{C j}}{V_{1} I_{1} T} \\
C I R=\frac{\sum_{j=1}^{n} W_{C j}}{\sum_{j=1}^{m} W_{L j}} .
\end{gathered}
$$

In Eq. (3), $S E$ is the stored energy and $P E$ is the pumping energy, which is defined as the input energy in a switching period ' $T$ '. $V_{1}$ and $I_{1}$ are the input voltage and current of the dc-dc converter; ' $m$ ' and ' $n$ ' are the number of inductors and capacitors, respectively. $W_{L j}$ and $W_{C j}$ represent the energy stored in $j^{\text {th }}$ inductor and capacitor, respectively. The damping time constant $\tau_{d}$ is given by the equation

$$
\tau_{d}=\frac{2 T \times E F}{1+C I R} C I R
$$

The time domain expression for output voltage is derived by inverse Laplace of Eq. (1) and given as

$$
V_{o}(t)=A+e^{-\alpha t}(b \cos \beta t+c \sin \beta t) .
$$

The constants $A, b$ and $c$ given in Eq. (6) can be found from the residues of the partial fraction expression of the transfer function given by Eq. (1). Similarly, the transfer function between inductor current and input voltage is given by Eqs. (7) and (8) for boost converter and buckboost converter, respectively, and the time domain expression is given by Eq. (9), which is derived by taking inverse Laplace of Eqs. (7) and (8):

$$
\begin{gathered}
\frac{I_{l}(s)}{V_{\text {in }}(s)}=\frac{M\left(1+\tau_{d} s\right)}{1+s \tau+s^{2} \tau \tau_{d}} \frac{1}{R(1-D)} \\
\frac{I_{l}(s)}{V_{\text {in }}(s)}=\frac{M\left(1+\tau_{d} s\right)}{1+s \tau+s^{2} \tau \tau_{d}} \frac{D}{R(1-D)^{2}} \\
i_{l}(t)=A_{2}+e^{-\alpha t}\left(b_{2} \cos \beta t+c_{2} \sin \beta t\right)
\end{gathered}
$$

where $A_{2}, b_{2}$ and $c_{2}$ in Eq. (9) can be found from the residues of partial fraction representation of Eqs. (7) and (8) and ' $D$ ' is the duty cycle of the dc-dc converter.

\section{Closed-loop voltage regulation control of dc-dc boost and buck-boost converter}

A closed-loop block diagram for the regulation of output voltage of a boost converter is shown in figure 3 .

The outer loop consists of a PI controller while the inner loop consists of a current controller. The output of PI controller block is the reference inductor current, which is given by the equation

$$
I_{l \_r e f}(s)=\left[V_{o \_r e f}(s)-V_{o}(s)\right]\left[\frac{k_{p} s+k_{i}}{s}\right]
$$


where $V_{o \_r e f}=V_{o}=V_{o \_n o m i n a l}$ is the nominal output voltage of a given dc-dc converter.

Substituting Eq. (1) in (10), we get

$$
\begin{gathered}
I_{l \_r e f}(s)=\left[\frac{V_{o \_r e f}}{s}-\frac{M \frac{V_{i n}}{s}}{1+s \tau+s^{2} \tau \tau_{d}}\right]\left[\frac{k_{p} s+k_{i}}{s}\right] \\
I_{l \_r e f}(s)=\left[\frac{V_{o \_r e f}\left(s+\frac{1}{\tau_{d}}\right)}{\left(s^{2}+s \frac{1}{\tau_{d}}+\frac{1}{\tau \tau_{d}}\right)}\right]\left[\frac{k_{p} s+k_{i}}{s}\right] \\
I_{l \_r e f}(s)=\left[\frac{V_{o \_r e f} k_{p}\left(s+\frac{1}{\tau_{d}}\right)\left(s+\frac{k_{i}}{k_{p}}\right)}{s\left(s^{2}+s \frac{1}{\tau_{d}}+\frac{1}{\tau \tau_{d}}\right)}\right] \\
i_{l \_r e f}(t)=A_{1}+e^{-\alpha t}\left(b_{1} \cos \beta t+c_{2} \sin \beta t\right)
\end{gathered}
$$

where $A_{1}, b_{1}$ and $c_{1}$ in Eq. (14) are the residues of partial fraction representation of Eq. (13).

Also, from Eqs. (7) and (8) for dc-dc boost converter and buck-boost converter, respectively, the actual inductor current is given by the equation

$$
\begin{gathered}
i_{l}(t)=A_{2}+e^{-\alpha t}\left(b_{2} \cos \beta t+c_{2} \sin \beta t\right) \\
\alpha=\frac{1}{2 \tau_{d}} ; \beta=\frac{\sqrt{4 \tau \tau_{d}-\tau^{2}}}{2 \tau \tau_{d}}
\end{gathered}
$$

where $A_{2}, b_{2}$ and $c_{2}$ are the residues of partial fraction representation of Eqs. (7) and (8) for boost and buck-boost converter, respectively. Also, $\alpha$ and $\beta$ in Eq. (16) are the real part and imaginary part, respectively, of the poles of the transfer function given by Eq. (1). The derivation of time domain expression for reference inductor current is given by Eqs. (11)-(14); similarly the derivation of time domain expression for actual inductor current is given by Eq. (15). The real and imaginary parts of the poles of Eq. (13) are given by Eq. (16). Also, the time domain expression for the reference inductor current in terms of controller parameters and actual inductor current in terms of circuit parameters for a given condition of $V_{o-\_}$ref and $V_{i n}$ is given by Eqs. (14) and (15), respectively. The rise time and settling time of the inductor current are governed by the Eq. (15), which describes the current response of the dc-dc converter. It is obvious that any attempt by the controller to drive the current faster than this time constant would lead to overshooting and instability. Hence the PI controller should generate a reference inductor current, such that it follows the inherent response nature of the power circuit, which would result in an optimum response in the actual inductor current as well as the output voltage. Equating Eqs. (14) and (15), the values of PI controller parameters could be derived. In this discussion the input voltage $V_{\text {in }}$ and load resistance $R$ are assumed to be constant, which is not normally the case. There would be certainly disturbances in the input voltage and the load resistance, which will vary in the ranges $V_{\text {in_min }}-V_{\text {in-_max }}$ and $R_{\min }-R_{\max }$, respectively. The worst case condition is considered for the design of control parameters, which would be $V_{\text {in_min }}$ for input voltage and $R_{\min }$ for the load resistance.

\subsection{Sliding mode current controller}

The basic principle of sliding mode control (SMC) involves design of a sliding surface and its control law, which would direct the trajectory of the state variables towards a desired origin. Normally, in a single switch dc-dc converter, the control law that adopts a switching function is given by the equation

$$
u=\frac{1}{2}(1+\operatorname{sign}(S))
$$

where ' $u$ ' is the switching function (logic state) of the converter's power switch and the state variable is the inductor current. Based on the general SMC theory, the state variable error is defined as the difference between actual and reference value, which forms the sliding function given by $S=i_{l \_a c t u a l}-i_{l_{\_} \text {ref }}$.

\section{Illustrative example on design of closed-loop PI- voltage regulator with a sliding mode current controller for a PV-fed dc-dc boost converter}

This section presents a design example on PI-regulator design of a PV-fed boost converter based on the procedure explained in section 3. The block diagram of the closedloop control scheme of a boost converter is shown in figure 4 and the simulation model implemented in MATLAB/ Simulink is shown in figure 5 . The outer loop consists of a PI regulator that accepts the voltage error from the comparator and generates the reference inductor current, which is followed by a current comparator and sliding mode

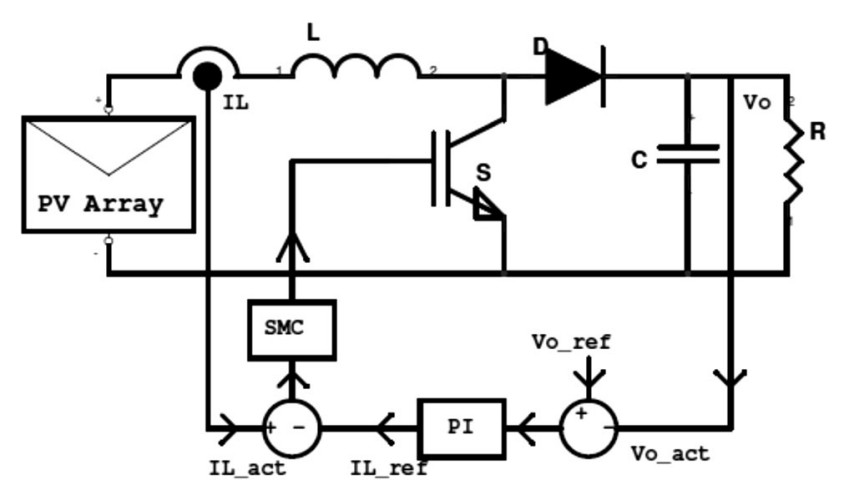

Figure 4. Block diagram for the closed-loop output voltage regulation of a PV-array-fed boost converter with a PI regulator and sliding mode current controller. 


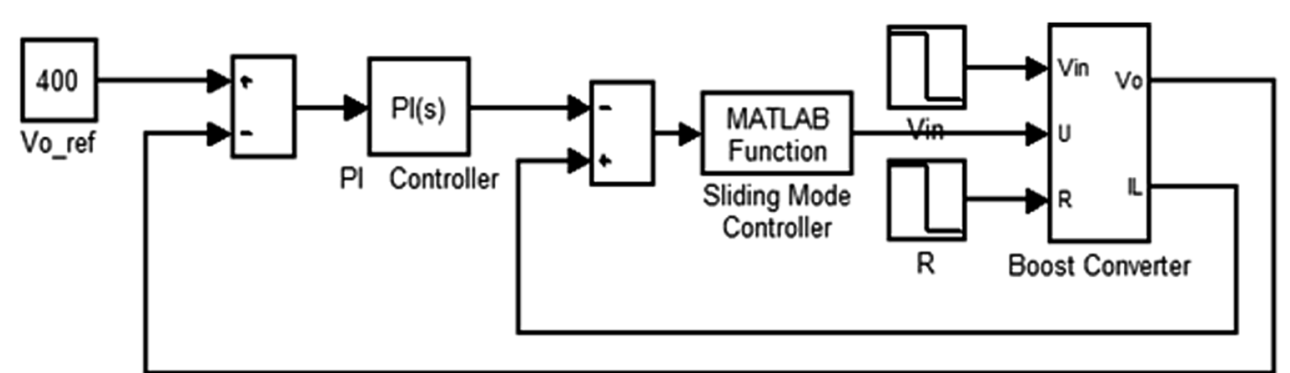

Figure 5. Simulation model for the closed-loop output voltage regulation of a boost converter with a PI regulator and sliding code current controller in MATLAB/Simulink.

Table 1. Design parameters for boost converter.

\begin{tabular}{ccc}
\hline $\begin{array}{l}\text { Sl. } \\
\text { no. }\end{array}$ & Parameters \\
\hline 1 & Nominal output voltage $V_{o \_ \text {nominal }}(\mathrm{V})$ & 400 \\
2 & Maximum output power $(\mathrm{W})$ & 1160 \\
3 & Load resistance $R(\Omega)$ & 138 \\
4 & Inductance $L(\mathrm{H})$ & 0.2 \\
5 & Capacitance C $(\mathrm{F})$ & $18 \times 10^{-6}$ \\
6 & Variation in input voltage $V_{\text {in_min }} \rightarrow V_{\text {in_max }}$ & $200-300$ \\
& $(\mathrm{~V})$ & \\
\hline
\end{tabular}

Table 2. Design parameters for PV array.

\begin{tabular}{ccc}
\hline $\begin{array}{l}\text { Sl. } \\
\text { no. }\end{array}$ & Parameters & Value \\
\hline 1 & Irradiation range $Q\left(\mathrm{~kW} / \mathrm{m}^{2}\right)$ & $0.4-0.9$ \\
2 & Temperature range $\left({ }^{\circ} \mathrm{C}\right)$ & $15-45$ \\
3 & Open-circuit voltage at STC (standard test & 21.29 \\
& conditions) $(\mathrm{V})$ \\
4 & Short-circuit current at STC (A) & 4.72 \\
5 & Number of PV panels in series (no.) & 13 \\
6 & Number of strings in parallel (no.) & 2 \\
7 & Variation in input voltage $V_{p v \_m i n} \rightarrow V_{p v \_m a x}$ & $200-300$ \\
& $(\mathrm{~V})$
\end{tabular}

current controller that generates the firing pulse for the boost converter based on the sign of the current error.

The design data considered for the boost converter is shown in table 1 and the PV array parameters are shown in table 2. The calculation of controller parameters for the design specifications is described here based on the design procedure explained in section 3 .

$$
M=\frac{v_{o}}{v_{\text {in }}}=\frac{1}{1-D} \Rightarrow \frac{400}{200}=\frac{1}{1-D} \Rightarrow D=0.5 .
$$

$D$ is the duty cycle.

Time constant and damping time constant are calculated using Eqs. (2) and (5):

$$
\begin{aligned}
& \tau=5.9 \mathrm{~ms}, \tau_{d}=2.5 \mathrm{~ms} \\
& \alpha=\frac{1}{2 \tau_{d}}=200, \quad \beta=\frac{\sqrt{4 \tau \tau_{d}-\tau^{2}}}{2 \tau \tau_{d}}=165.9275
\end{aligned}
$$

From Eq. (8), the expression for PV array current, which is the same as inductor current for the given condition, is

$$
\begin{aligned}
I_{p v}(s) & =\frac{M\left(1+\tau_{d} s\right)}{1+s \tau+s^{2} \tau \tau_{d}} \frac{V_{p v \_ \text {min }}}{s . R(1-D)} \\
& =\frac{2\left(1+2.5 \times 10^{-3} s\right)}{1+5.9 \times 10^{-3} s+1.4750 \times 10^{-5} s^{2}} \frac{200}{s .135(1-0.5)} \\
i_{p v}(t) & =5+e^{-200 t}(-5 \cos 165.9 t-0.933 \sin 165.9 t) .
\end{aligned}
$$

Similarly, from Eq. (13), the reference PV array current is

$$
\begin{aligned}
I_{p v \_r e f}(s)= & {\left[\frac{400 k_{p}(s+400)\left(s+\frac{k_{i}}{k_{p}}\right)}{s\left(s^{2}+400 s+67796.6\right)}\right] . } \\
i_{p v \_r e f}(t)= & 2.3694 k_{i}+e^{-200 t}\left[\left(400.32 k_{p}-2.3694 k_{i}\right)\right. \\
& \left.\times \cos 165.9 t+\left(480.92 k_{p}-0.445 k_{i}\right) \sin 165.9 t\right] .
\end{aligned}
$$

Equating $i_{p v}(t)$ and $i_{p v \_r e f}(t)$, we get $k_{p}=0, k_{i}=2.101$.

\subsection{Simulation results of voltage-regulated boost converter}

The simulation of PV-array-fed boost converter in closed loop is implemented using the controller constants calculated in the previous section, considering the disturbance in irradiation as well as temperature incident on the PV array and also with varying load conditions. The change in temperature causes a change in PV array voltage; similarly, the change in irradiation results in change in current capacity of the PV array. Normally the change in PV array voltage or current will not be instantaneous; rather it would be gradual based on the climatic conditions. But as a worst case a step change in irradiation as well as temperature has 
been considered to evaluate the robustness of the controller. The step response for the minimum input voltage and maximum input voltage considered for design is shown in figure $6 \mathrm{a}$ and $\mathrm{b}$, respectively. The response for change in irradiation and temperature is shown in figure $7 \mathrm{a}$ and $\mathrm{b}$, respectively. Also, the response for a simultaneous change in irradiation as well as temperature and load disturbance is shown in figure $8 \mathrm{a}$ and $\mathrm{b}$, respectively. From the results, it is observed that there is absolutely no overshoot or undershoot present in the output voltage for both extremes of input voltage step change from zero value. Also, the maximum value of overshoot during irradiation, temperature and load variations is found to be very small in magnitude with a reduced settling time. The performance indices of the controller, including overshoot, settling time and rise time, under different conditions are tabulated in table 3 .

\subsection{Stability analysis of the proposed controller}

As explained in the previous sections the controller is designed such that the system operates in stable condition within the boundary considered for the design of controller, which includes the disturbances in irradiation incident on $\mathrm{PV}$ array, temperature of the $\mathrm{PV}$ array and variations in load. The inherent inductor current response (which is also the PV array current) of the dc-dc converter for the worst case condition is governed by Eq. (18). Any effort by the controller to make the converter to respond faster than this would lead to overshooting and instability. The controller response of outer loop with PI regulator, which generates the reference inductor current as given by Eq. (19), needs to be limited by the inherent inductor current response of the $\mathrm{dc}-\mathrm{dc}$ converter. Therefore the stability of the outer loop is achieved by appropriate selection of controller gains in order to make the reference inductor current buildup well within the inherent inductor current response capability of the $\mathrm{dc}-\mathrm{dc}$ converter for the entire working range in consideration.

$$
\begin{aligned}
i_{p v}(t)=5+ & e^{-200 t}(-5 \cos 165.9 t-0.933 \sin 165.9 t) \\
i_{p v \_r e f}(t)= & 2.394 k_{i}+e^{-200 t}\left[\left(400.32 k_{p}\right.\right. \\
& \left.-2.3694 k_{i}\right) \cos 165.9 t+\left(480.92 k_{p}\right. \\
& \left.\left.-0.445 k_{i}\right) \sin 165.9 t\right]
\end{aligned}
$$

The sliding surface in a SMC-controlled PV-fed boost converter is defined by Eq. (20). The condition for stability corresponding to the two modes of operation, namely the
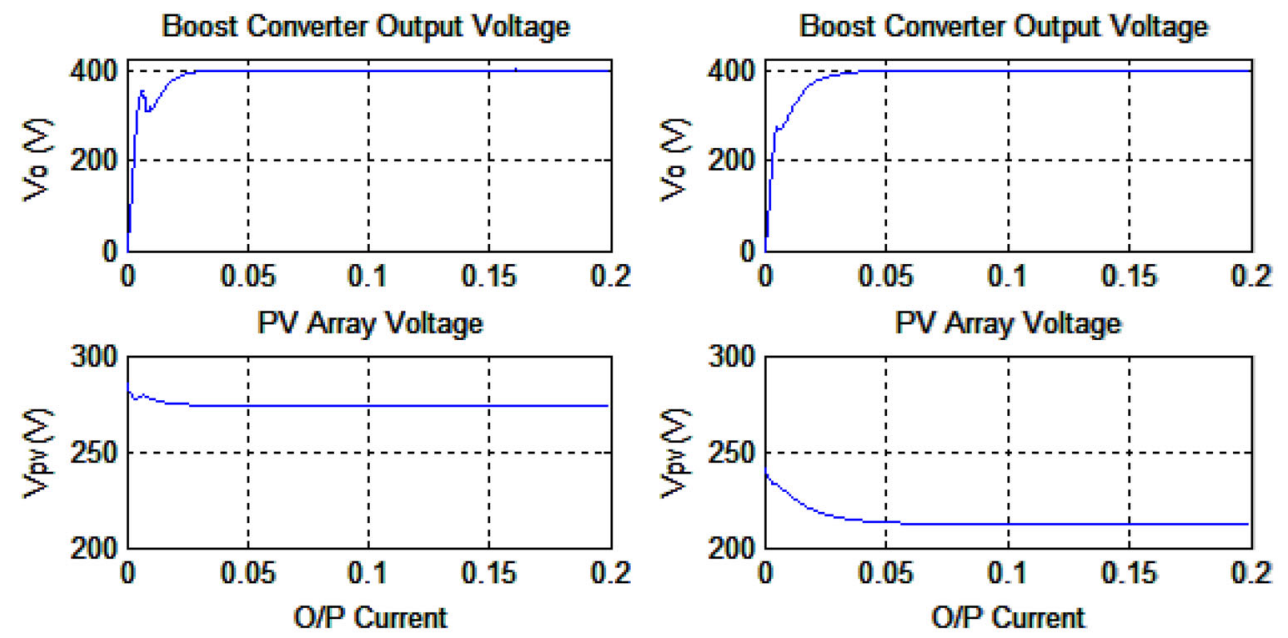

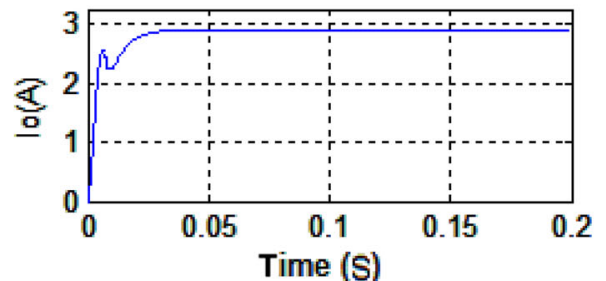

(a)

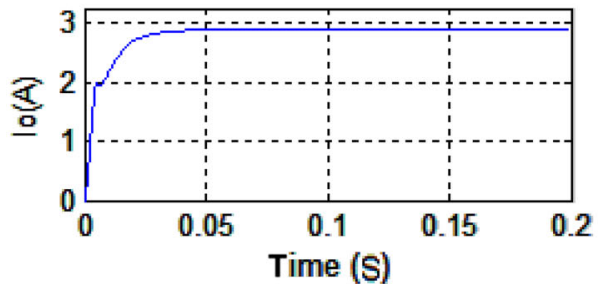

(b)

Figure 6. Simulation results of a PV-array-fed boost converter with a PI regulator and SMC using MATLAB/Simulink. (a) Step response for maximum input voltage $V_{p v}=280 \mathrm{~V}, R=138 \Omega$, irradiation $=0.62 \mathrm{~kW} / \mathrm{m}^{2}$ and temperature $=15^{\circ} \mathrm{C}$. (b) Step response for minimum input voltage $V_{p v}=210 \mathrm{~V}, R=138 \Omega$, irradiation $=0.62 \mathrm{~kW} / \mathrm{m}^{2}$ and temperature $=45^{\circ} \mathrm{C}$. 

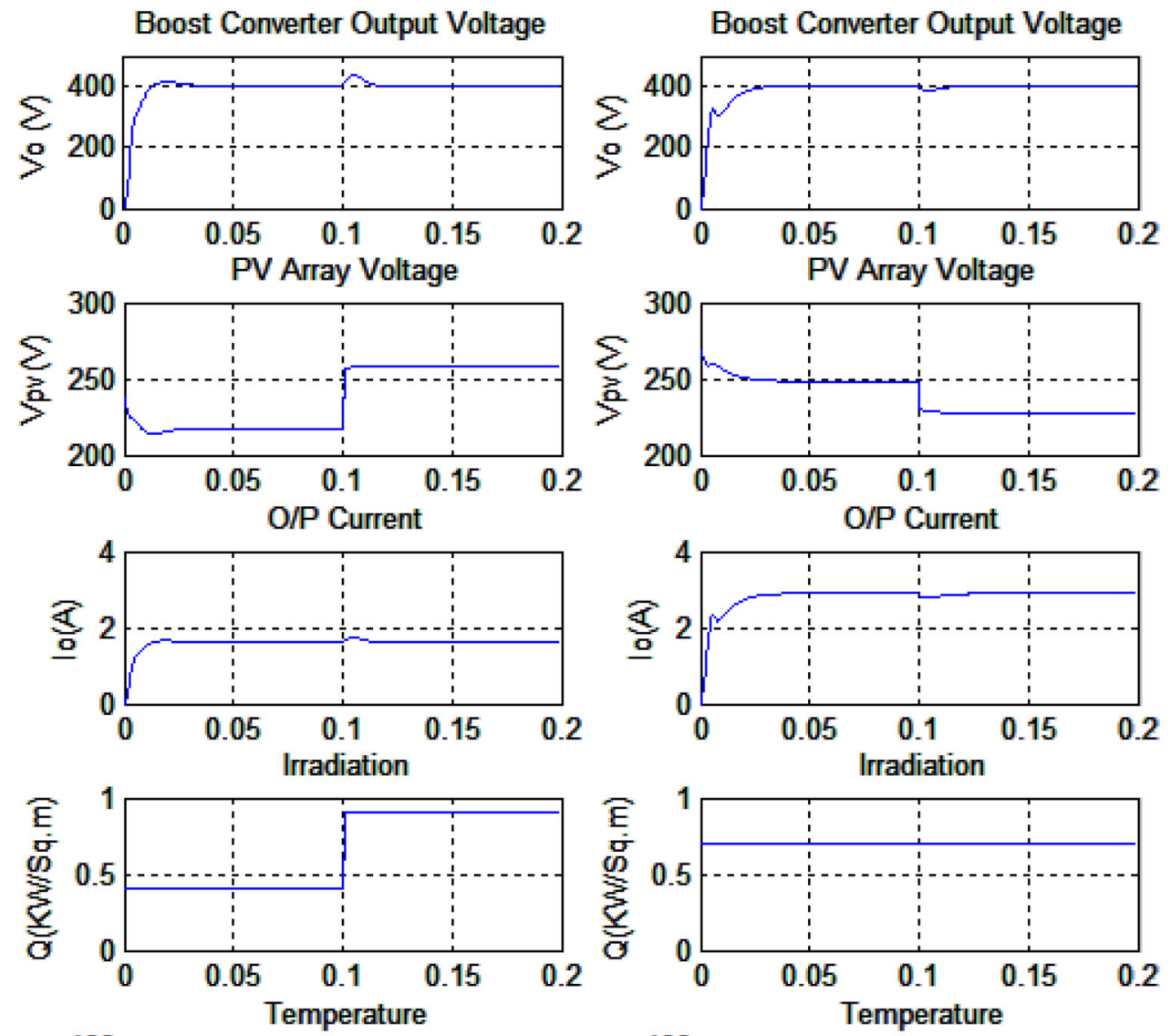

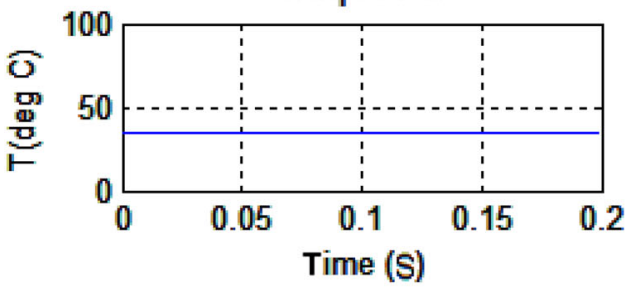

(a)

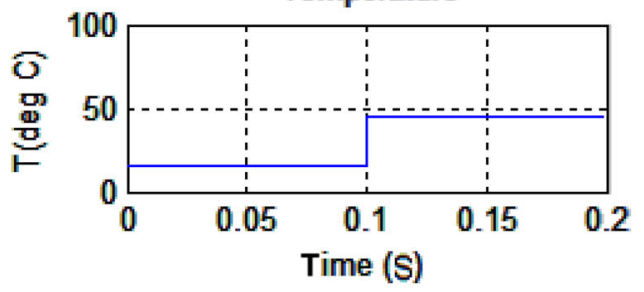

(b)

Figure 7. Simulation results of PV-array-fed boost converter with a PI regulator and SMC. (a) Step response with constant temperature $35^{\circ} \mathrm{C}$ and varying irradiation from 0.4 to $0.9 \mathrm{~kW} / \mathrm{m}^{2}$ at $0.1 \mathrm{~s}$. (b) Step response for constant irradiation of $0.7 \mathrm{~kW} / \mathrm{m}^{2}$ and varying temperature from 15 to $45^{\circ} \mathrm{C}$ at $0.1 \mathrm{~s}$.

reaching mode and the sliding mode, has been well illustrated in the literature [20].

$$
\begin{gathered}
S=i_{p v \_a c t u a l}-i_{p v \_r e f}=0 \\
\lim _{S \rightarrow 0^{-}} \frac{d s}{d t}>0 \Rightarrow u=1 \\
\lim _{S \rightarrow 0^{+}} \frac{d s}{d t}<0 \Rightarrow u=0 \\
-\frac{V_{o}-V_{p v}}{L}<\frac{d i_{p v \_r e f}}{d t}<\frac{V_{p v}}{L} .
\end{gathered}
$$

The switching law of the sliding mode controller is derived from the surface reachability condition given in
Eq. (21). The condition for local stability in order to confine within the sliding surface is given in Eq. (22).

The plot of output voltage versus inductor current, which are the two state variables of the dc-dc converter, with variations in temperature, irradiation and load is shown in figure $9 \mathrm{a}, \mathrm{b}$ and $\mathrm{c}$, respectively. It can be observed from figure 9a that the system reaches the stable state with output voltage reaching its desired value of $400 \mathrm{~V}$ for all values of temperature ranging from 5 to $45^{\circ} \mathrm{C}$. Also, with respect to variation in irradiation, the system is stable, delivering its rated load for irradiation value greater than $0.4 \mathrm{~kW} / \mathrm{m}^{2}$, till $1.2 \mathrm{~kW} / \mathrm{m}^{2}$, as shown in figure $9 \mathrm{~b}$; similarly, the controller is capable of maintaining stability up to 1.5 times the rated load as shown in figure 9c, beyond 
Boost Converter Output Voltage
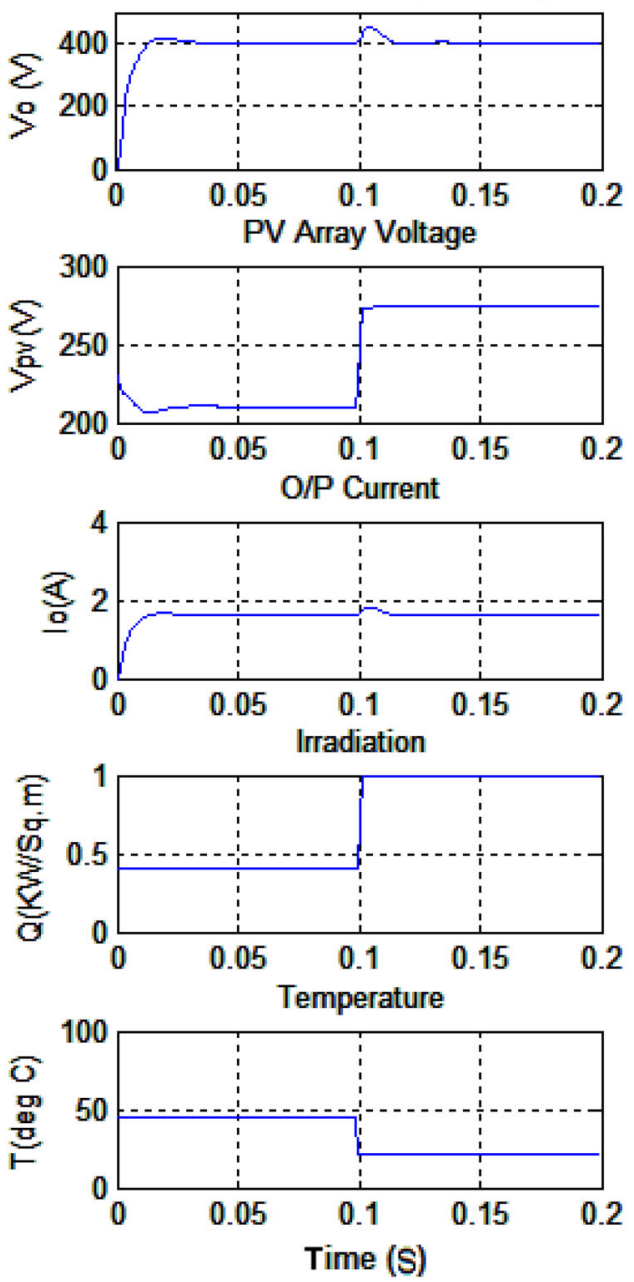

(a)
Boost Converter Output Voltage
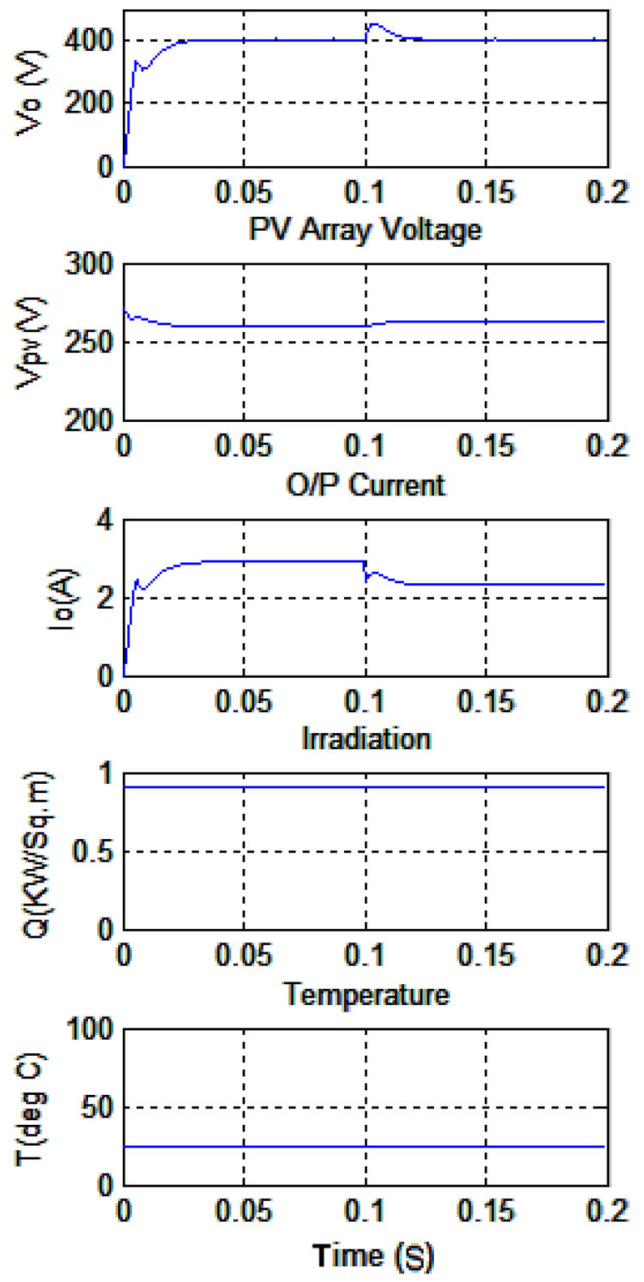

(b)

Figure 8. Simulation results of a PV-array-fed boost converter with a PI regulator and sliding mode current controller using MATLAB/ Simulink. (a) Step response for simultaneous change in irradiation from 0.4 to $1.0 \mathrm{~kW} / \mathrm{m}^{2}$ and change in temperature from 45 to $20^{\circ} \mathrm{C}$ at $0.1 \mathrm{~s}$. (b) Step response for change in load resistance from 148 to $185 \Omega$ at $Q=0.9 \mathrm{~kW} / \mathrm{m}^{2}$ and temperature $=25^{\circ} \mathrm{C}$.

Table 3. Dynamic response of PV-array-fed boost converter with the proposed controller design.

\begin{tabular}{|c|c|c|c|c|}
\hline Disturbances considered for simulation & $\begin{array}{l}\text { Delay } \\
\text { time }(\mathrm{ms})\end{array}$ & $\begin{array}{l}\text { Settling } \\
\text { time (ms) }\end{array}$ & $\begin{array}{c}\text { Peak overshoot }(\% \text { of } \\
\left.V_{\text {O_nominal }}\right)\end{array}$ & $\begin{array}{l}\text { Steady-state } \\
\text { error }(\mathrm{V})\end{array}$ \\
\hline Minimum PV array voltage at $210 \mathrm{~V}$ & 5 & 25 & 0 & \pm 1 \\
\hline Maximum PV array voltage at $280 \mathrm{~V}$ & 5 & 30 & 0 & \pm 1 \\
\hline Change in irradiation from 0.4 to $0.9 \mathrm{~kW} / \mathrm{m}^{2}$ at $0.1 \mathrm{~s}$ & NA & 15 & 20 & \pm 2 \\
\hline Change in temp. from 15 to $45^{\circ} \mathrm{C}$ & NA & 15 & 18 & \pm 2 \\
\hline $\begin{array}{l}\text { Simultaneous change in irradiation from } 0.4 \text { to } 1.0 \mathrm{~kW} / \mathrm{m}^{2} \text { and } \\
\text { change in temperature from } 45 \text { to } 20^{\circ} \mathrm{C}\end{array}$ & NA & 15 & 40 & \pm 2 \\
\hline Change in load resistance from 148 to $185 \Omega$ & NA & 15 & 38 & \pm 2 \\
\hline
\end{tabular}

which the output voltage falls. The stability of the inner current loop depends on the maximum allowable error from the sliding surface. The state plane $(x-\dot{x}$ plane $)$ plot, showing the variation of inductor current error and its rate of change, is shown in figure 10 for all the disturbance conditions. It can be observed that the error converges 


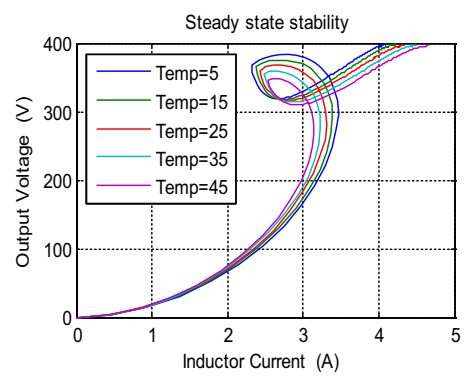

(a)

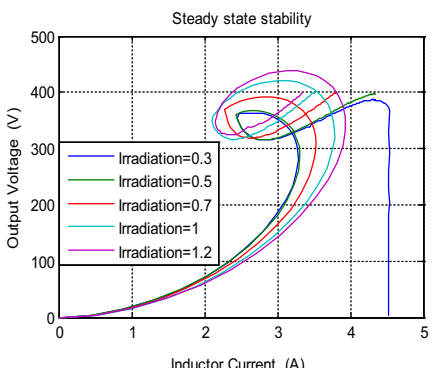

(b)

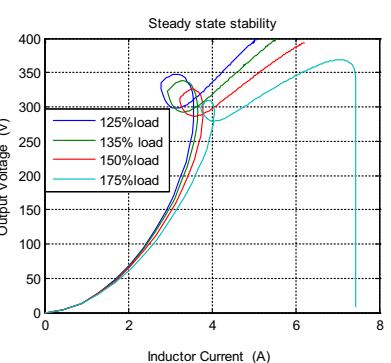

(c)

Figure 9. Stability analysis curves. (a) Constant irradiation at $0.5 \mathrm{~kW} / \mathrm{m}^{2}$ and rated load with varying temperature. (b) Constant temperature at $45^{\circ} \mathrm{C}$ and rated load with varying irradiation. (c) Constant irradiation at $0.7 \mathrm{~kW} / \mathrm{m}^{2}$ and temperature at $45^{\circ} \mathrm{C}$ with varying load.

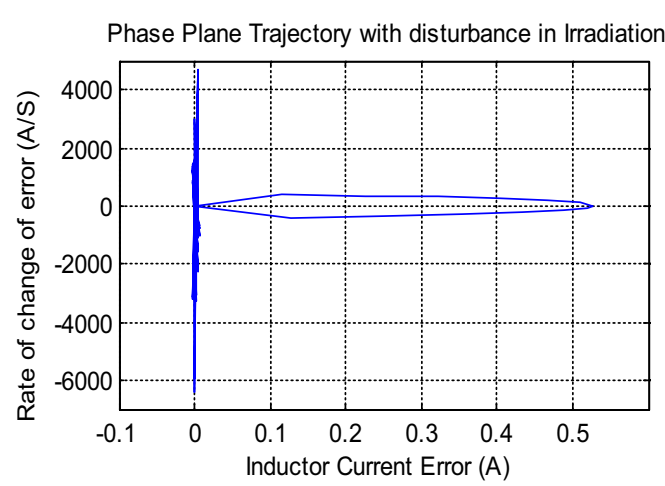

(a)

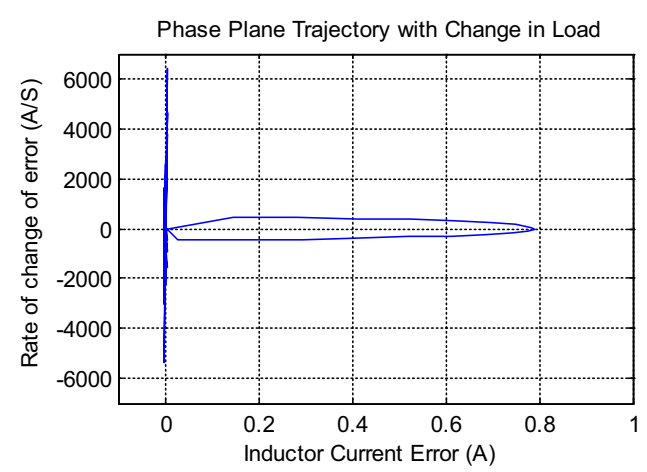

(c)

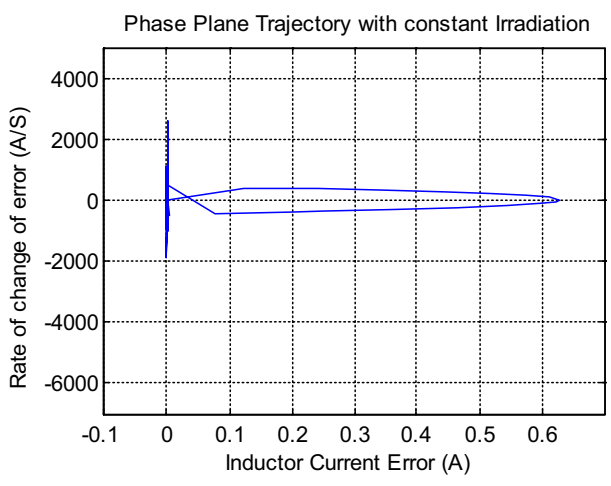

(b)

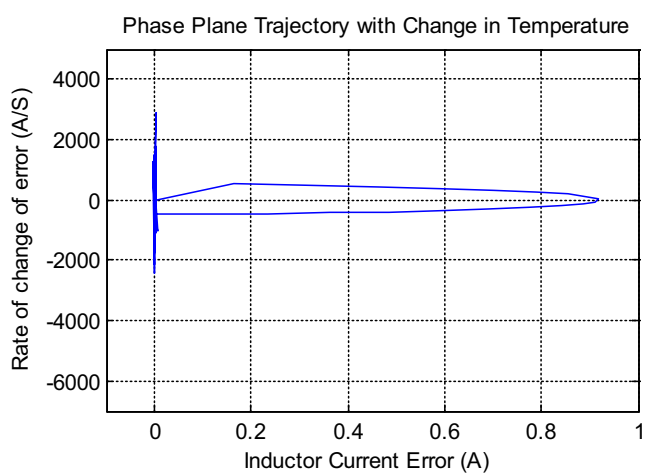

(d)

Figure 10. Phase plane trajectory plot between inductor current error and rate of change of error (a) with disturbance in irradiation, (b) without any disturbances, (c) with disturbances in load and (d) with disturbance in temperature.

towards the sliding surface $\left(S=i_{l \_a c t u a l}-i_{l \_r e f}=0\right)$ for all the disturbance conditions in irradiation, temperature and load, which verifies the reaching mode. Confinement within the sliding surface is verified using the plot of rate of change of inductor reference current as shown in figure 11, which shows that the compliance of Eq. (22) is necessary for local stability. In figure 11, the rate of change of inductor reference current is out of the boundary defined by Eq. (22) initially for a short period of time. This corresponds to the reaching mode of operation, after which it reaches zero, signalling steady state. This is followed by a sudden fall at $0.05 \mathrm{~s}$ due to disturbance in load, but still 


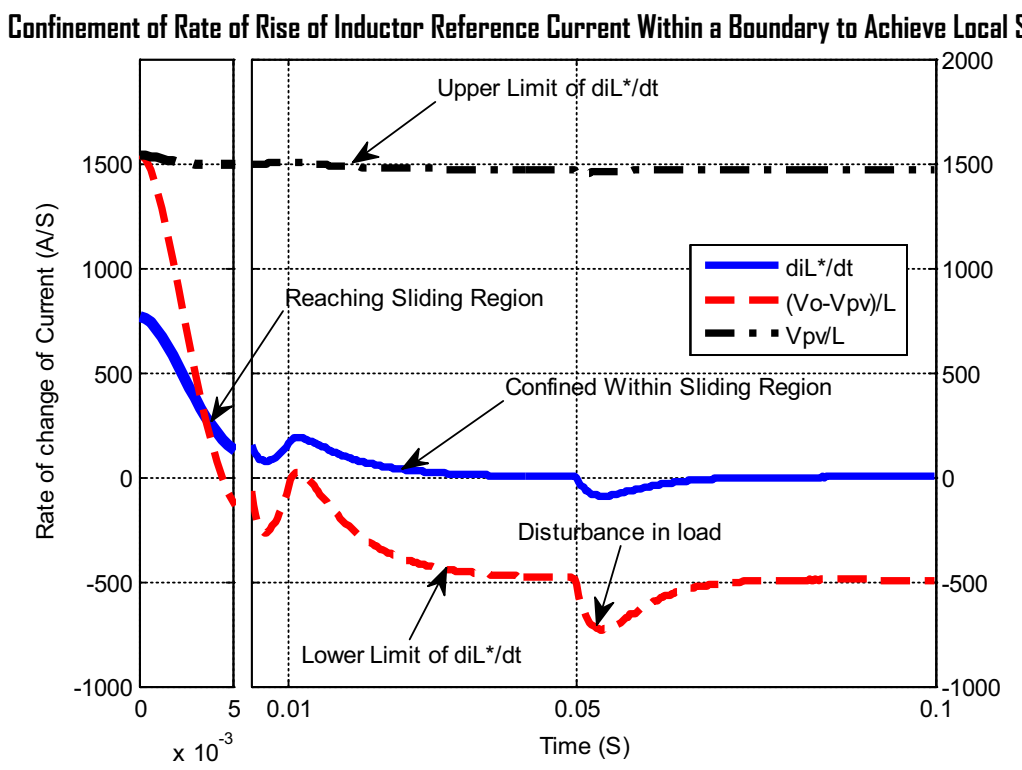

Figure 11. Rate of change of inductor reference current confined within a defined boundary complying with the condition for local surface stability under disturbances in load varying from $150 \%$ to rated load at $0.05 \mathrm{~s}$.

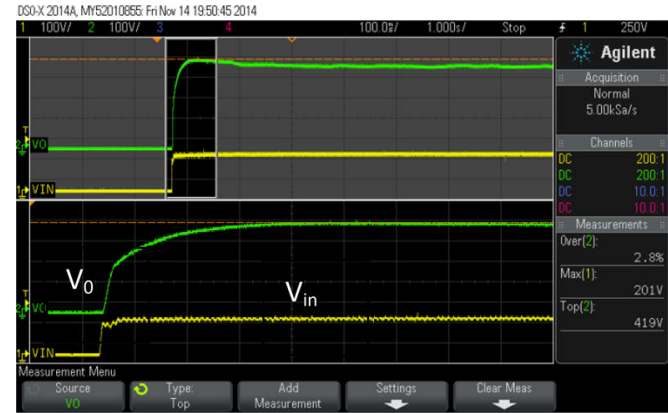

(a)

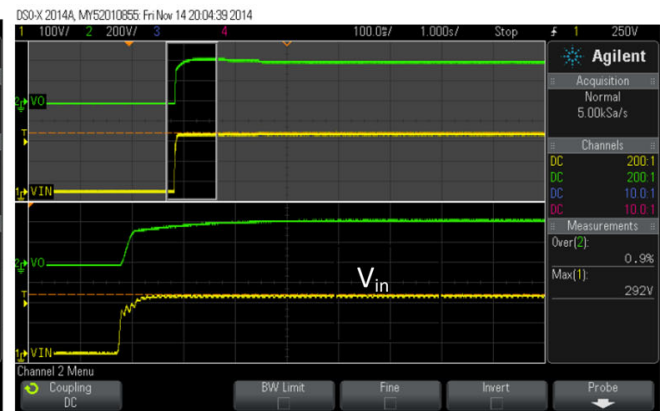

(b)

Figure 12. Step response of the boost converter for input PV voltage: (a) $V_{P V}=190 \mathrm{~V}$ and (b) $V_{P V}=292 \mathrm{~V}$.

confining within its prescribed limits. Therefore the cascaded PI-SMC controller sustains stable operation for all kind of disturbances.

\section{Hardware implementation and field test validation}

This section presents the real-time field test results and performance analysis of the proposed controller. The proposed cascaded PI-SMC controller is implemented using a microcontroller TMS320F28027. A field test is conducted on this controller with a stand-alone PV-array-fed boost converter feeding a resistive load. Weather sensors for monitoring irradiation incident on the module and module temperatures were used along with voltage and current sensors. A data logger is used to monitor these data over a period of time. The step response of the boost converter for the two extremes of the PV voltage considered for the controller design $\left(V_{P V_{-} \min }=200 \mathrm{~V}\right.$ and $\left.V_{P V \_ \text {max }}=300 \mathrm{~V}\right)$ is shown in figure $12 \mathrm{a}$ and $\mathrm{b}$, respectively. Also the response of the boost converter for abrupt fall and rise in PV voltage is shown in figure 13a and b, respectively. In order to verify the performance of the controller under realtime conditions, the PV voltage, output voltage and load current along with module irradiation and temperature were monitored and data-logged continuously for a period of $10 \mathrm{~min}$. This duration witnessed appreciable changes in irradiation due to passing of clouds as well as a slight change in temperature. A pyranometer is used, which is installed in the same inclination as the PV module to get the module irradiance along with a temperature sensor, which is installed beneath the PV module, as shown in figure 14 . The response of the boost converter for change in 


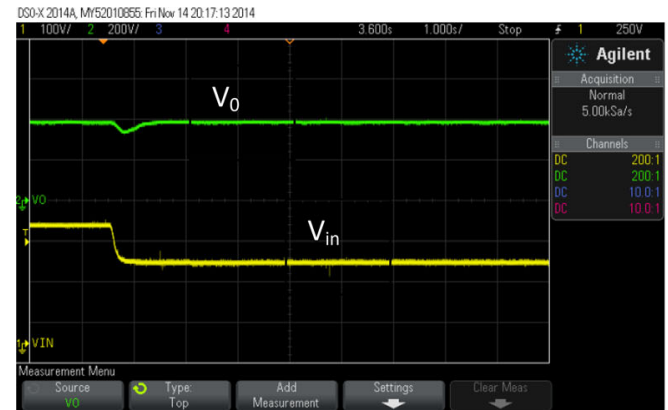

(a)

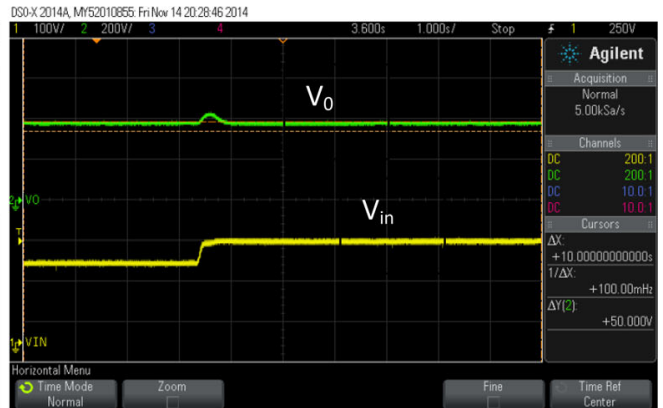

(b)

Figure 13. Response of the boost converter for disturbances in input PV voltage due to change in load/irradiation: (a) fall in PV voltage and (b) rise in PV voltage.

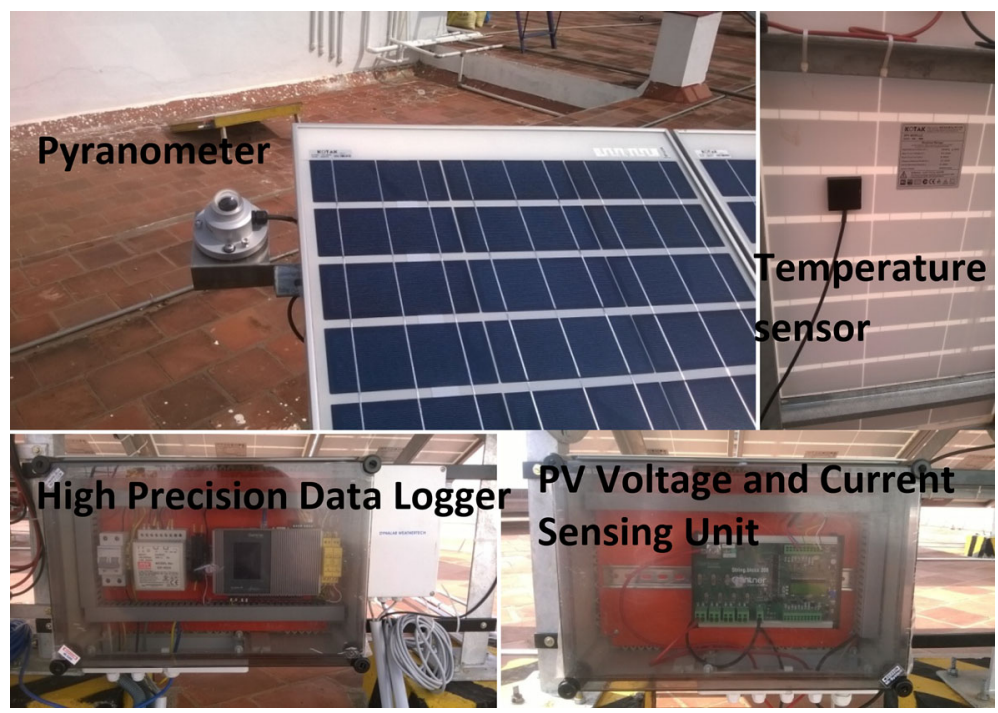

Figure 14. Output voltage response of the PV-fed boost converter captured over a period of 10 min under disturbances in input PV voltage due to change in irradiation, temperature and load.

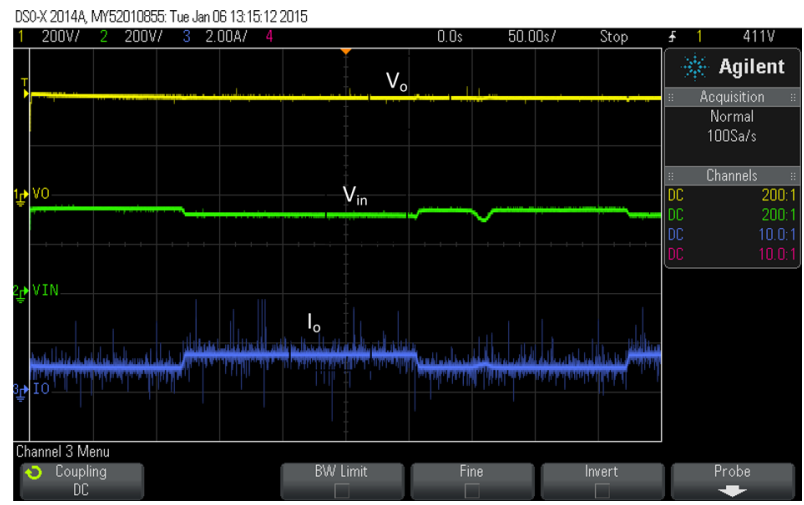

Figure 15. Output voltage response of the PV-fed boost converter captured over a period of $10 \mathrm{~min}$ under disturbances in input PV voltage due to change in irradiation, temperature and load.

irradiation, temperature and load is shown in figure 15 . The data points of waveforms shown in figure 15 are captured and plotted along with the weather data captured for the same duration as shown in figure 16. The entire hardware set-up is shown in figure 17. It can be observed from the field test results that the output voltage of the boost converter is well regulated using the proposed controller under all kinds of disturbances. Also the results coincide well with the simulation results.

\section{Conclusion}

A new technique based on EF concept has been developed for the first time, for feedback controller design, and a multi-loop control of dc-dc boost converter and dc-dc buck-boost converter for an off-grid PV application is presented in this paper. The generalized transfer function of dc-dc converter based on EF and time constant concept has been utilized for the design of the PI regulator. Analytical expressions have been presented for the selection of controller gains. Theoretical and simulation results along with 


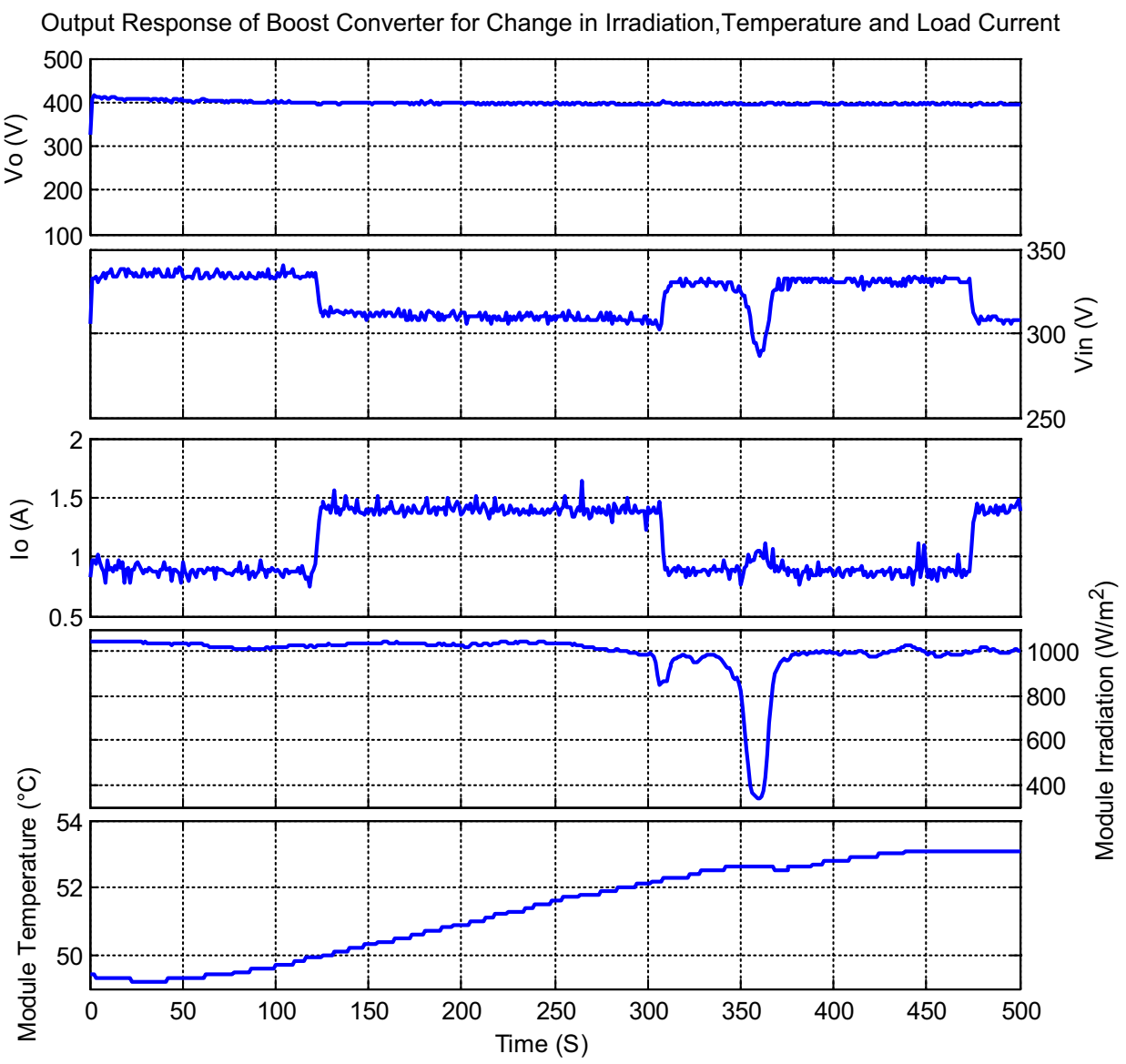

Figure 16. Output voltage response of the PV-fed boost converter captured over a period of 10 min under disturbances in input PV voltage due to change in irradiation, temperature and load. Waveforms are plotted using real-time data of irradiation; temperature, voltage and current are captured using weather, voltage and current sensors with a data logger.
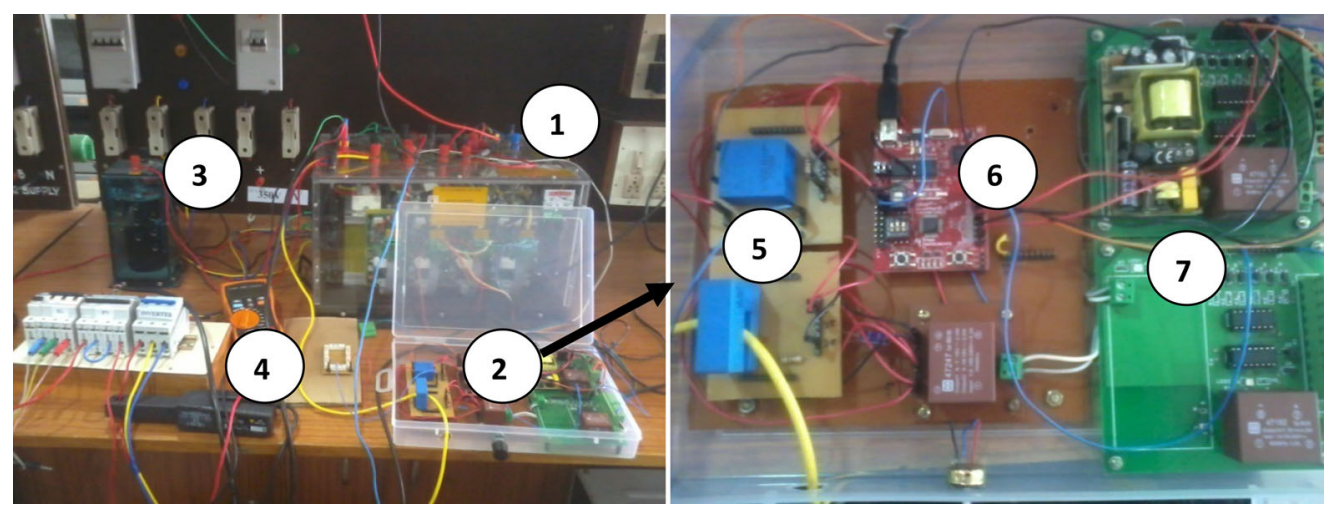

Figure 17. Hardware set-up of the boost converter with voltage regulation controller. 1. Boost converter power circuit, 2 . proposed controller implemented in hardware, 3. power capacitor, 4. current-sensing probe, 5. Hall-effect voltage and current sensors, 6. TMS320F28027 microcontroller and 7. PWM interface circuit.

the stability analysis and performance analysis are presented to verify and validate the new methodology. The illustrative example of the proposed controller design based on the EF model, along with the simulation results, shows the appreciable dynamic performance of PV-array-fed boost converter for all kinds of disturbances with negligible 
overshoot and steady-state error. Also, the hardware implementation and real-time performance analysis based on field test results shows that the output voltage is well regulated under all kinds of weather and load disturbances. The field test results validate that the controller is capable of regulating the output voltage of the boost converter fed by a PV array, which has nonlinear characteristics, unlike a normal dc source. Hence this proposed controller could be considered as an attractive solution for renewable energy applications like PV- or fuel-cell-fed dc-dc converter, where the variations are stochastic in nature. In particular, the proposed work could be used for any off-grid power generation system based on renewable sources in a batteryless-mode operation. This method could be used for the voltage regulator design of other $\mathrm{dc}-\mathrm{dc}$ converters also.

\section{Acknowledgements}

The authors acknowledges the All India Council of Technical Education (AICTE), Ministry of Human Resource and Development, Government of India, for award of National Doctoral Fellowship to the first author of this article, for pursuing his Ph.D, under which the present research work is carried out.

\section{References}

[1] Matsuo H, Wenzhong L, Kurokawa F, Shigemizu T and Watanabe N 2004 Characteristics of the multiple-input DCDC converter. IEEE Trans. Ind. Electron. 51: 625-631

[2] Todorovic M H, Palma L and Enjeti P N 2008 Design of a wide input range $\mathrm{dc}-\mathrm{dc}$ converter with a robust power control scheme suitable for fuel-cell power converters. IEEE Trans. Ind. Electron. 55: 1247- 1255

[3] Cuk S and Middlebrook D R 1983 Advances in switchedmode power conversion part I. IEEE Trans. Ind. Electron. 30: $10-19$

[4] Cuk S and Middlebrook D R 1983 Advances in switchedmode power conversion part II. IEEE Trans. Ind. Electron. 30: 19-29

[5] Davoudi A, Jatskevich J and De Rybel T 2006 Numerical state space average value modeling of PWM DC-DC converters operating in DCM and CCM. IEEE Trans. Power Electron. 21: 1003-1012

[6] Sira-Ramirez H, Perez-Moreno R A, Ortega R and GarciaEsteban M 1997 Passivity based controllers for the stabilization of DC-DC power converters. Automatica 33: 499-513

[7] Sun J, Mitchell D M, Greuel M F, Krein P T and Bass R M 2001 Averaged modeling of PWM converters operating in discontinuous conduction mode. IEEE Trans. Ind. Electron. 16: $482-492$

[8] Aldo B, Corsanini D, Landi A and Sani L 2006 Circle based criteria for performance evaluation of controlled DC-DC switching converters. IEEE Trans. Ind. Electron. 53: 1862-1869

[9] Cominos P and Munro N 2002 PID controllers: recent tuning methods and design to specification. IEE Power Contr. Theor. Appl. 149: 46-53

[10] Escobar G, Ortega R, Sira Ramirez H, Vilain J P and Zein I 1999 An experimental comparison of several nonlinear controllers for power converters. IEEE Contr. Syst. Mag. 19: $66-82$

[11] He Y and Luo F L 2006 Sliding mode control of DC-DC converters with constant switching frequency. IEE Power Contr. Theor. Appl. 153: 37-45

[12] Hung J Y Gao W and Hung J C 1993 Variable structure control: a survey. IEEE Trans. Ind. Electron. 40: 2-22

[13] Tan S C, Lai Y M, Tse C K, Salamero L M and Wu C K 2007 A fast response sliding mode controller for boost-type converters with a wide range of operating conditions. IEEE Trans. Ind. Electron. 54: 3276-3286

[14] Cheng K H, Hsu C F, Lin C M, Lee T T and Li C 2007 Fuzzy neural sliding mode control for DC-DC converters using asymmetric Gaussian membership functions. IEEE Trans. Ind. Electron. 54: 1528-1536

[15] Gupta T, Boudreaux R R, Nelms R M and Hung J Y 1997 Implementation of a fuzzy controller for DC-DC converters using an inexpensive 8-b microcontroller. IEEE Trans. Ind. Electron. 44: 661-668

[16] Perry A G, Feng G, Liu Y F and Sen P C 2007 A design method for PI like fuzzy logic controllers for DC-DC converter. IEEE Trans. Ind. Electron. 54: 2688-2696

[17] Luo F L, Ye H and Muhammad H R 2005 Digital power electronics and applications. Elsevier Academic Press, San Diego, CA

[18] Luo F L and Ye H 2007 Small signal analysis of energy factor and mathematical modelling for power DC-DC converters. IEEE Trans. Power Electron. 22: 69-79

[19] Cervantes I, Garcia D and Noriega D 2004 Linear multiloop control of quasi-resonant converters. IEEE Trans. Power Electron. 18: 1194-1201

[20] Sira-Ramirez H 1987 Sliding motions in bilinear switched networks. IEEE Trans. Circuits Syst. 34: 919-933 